* Corresponding author Phone +421556022466 E-mail address: solc@kme.zcu.cz (M. Šolc)

Article information Article history: AMS-Volume15-No.1-00104-11 Received 23 March 2011

Accepted 26 May 2011

Available online 26 August

\section{From Partial Factors Design to the SBRA Probabilistic Method}

\author{
Plánička František ${ }^{\text {a }}$ Šolc Martin a* ${ }^{\text {, }}$, Marek Pavel ${ }^{\mathrm{a}}$ \\ ¿Department of Mechanics, University of West Bohemia, Univerzitní 22, Plzeň, Czech Republic
}

\section{BIOGRAPHICAL NOTES}

František Plánička, prof. Ing. CSc. (born in 1936) professor at the Department of Mechanics, Faculty of Applied Sciences University of West Bohemia Czech Republic. 1954 finished grammar school at Klatovy, 1959 graduated at the college of Mechanical and Electrical Engineering in Pilsen field of study Machine tools and Machining with the degree of Ing. (MSc level). In 1971 defended thesis in the field of Physical Metallurgy an Ultimate States of Materials with degree CSc. (Ph.D. level), 1976 senior lecturer Professor at the branch of Mechanics of Materials in 1984. He is focused on boundary states of materials and experimental mechanics. Academic and professional positions as head of department, vice-rector, rector, chairman of the professional group of Experimental Mechanics of the Czech Society for Mechanics a member of the committee of that society. Author or co-author of many articles presented in several professional journals and at national and international conferences in the field of Moire Method and its applications to plastic deformations and to fracture mechanics. Co-author of patent of invention: The Moire Method and its Modification for Realization of Procedure Designing using Personal Computer.

Martin Šolc, Ing. (born in 1984) after graduating from the Czech Technical University in Prague, faculty of Civil Engineering, in 2009, he started studying in the Doctoral Study Course at the University of Western Bohemia in Plzeň, faculty of Applied Sciences, Department of Mechanics. His main areas of interest include structural reliability, probabilistic methods and experimental mechanics.

Pavel MAREK, Professor Dipl. Ing. PhD., DrSc., F.ASCE (born in 1932) professor and Senior Researcher at West-Bohemia-University in Pilsen (Department of Mechanics Faculty of Applied Sciences), Czech Republic / Graduated:Dipl.Ing. 1955, Assoc. Professor 1967, DrSc. and Senior Researcher 1989, (Full) Professor and Senior Researcher at the Academy of Sciences of the Czech Republic, Institute of Theoretical and Applied Mechanics (ITAM) 1997. Professor and Supervisor of numerous PhD students. Research, teaching and consulting activities abroad: Senior Consulting Engineer in India 1960 to 1964. Designed steel structures for a steel foundry in Ranchi Bihar, Assoc. Researcher, 1968-1971, U.S.A. and Visiting Professor, 1986,Canada,Visiting Professor at universities in the U.S.A., 19881997, Fellow of ASCE, Member of Engineering Academy of Czech Republic, Member of several professional associations, including, e.g., ČSSI, ČKAIT and SEl. During the period 1986 to 2010 was author or co-author of 400 publications on Simulation Based Structural Reliability Assessment and related topics (see http://www.sbra-anthill.com/).

\section{KEYWORDS}

Probabilistic Approach, SBRA, Reliability, Structural Analysis, Durability, Load Duration Curves 


\section{ABSTRACT}

Two decades ago, a computer revolution made available personal computers to all designers of load carrying structures. Through proposing and gradual improving of the probabilistic method SBRA (Simulation Based Reliability Assessment), significant adjustment of the assessment of structural safety, serviceability and durability is assured. The probabilistic approach and simulation technique have introduced new definitions of loads, achieving a higher precision for their combinations and allowing to consider multicomponent problems. The very essence of the SBRA method consists in repeated calculations of relatively simple equations, where input variables can be either constant or defined by histograms (yield limit, loads, imperfections, etc.). Together with powerful numerical tools such as the Monte Carlo simulation, the SBRA method allows for determining not only the probability of failure of a determined element, but also deformation criteria to meet serviceability requirements, and accumulation of damage such as fatigue or corrosion.

\section{Introduction}

The origin of the method that later became known as SBRA dates back to the year 1987, when Pavel Marek and Milan Gustar purchased one of the first personal computers in the former Czechoslovakia. Although the parameters of that $\mathrm{OC} X \mathrm{X}$ computer seem ridiculously limited today $(4,77 \mathrm{MHz}$ frequency, $20 \mathrm{MB}$ hard disk) the two engineers immediately recognized that this could mean a qualitative advancement in the assessment of structures.

The first attempts to use the computer's potential were aimed at determining loads and their combinations using the Monte Carlo simulation process. In order to perform this, the definition of loads had to be changed, replacing the commonly used "characteristic value" and "load coefficient" with the concept of Load Duration Curves (discussed in detail in the following section). It was clear that this laid the basis for one "side of the equation". To attain the other side, structural parameters had to be introduced into the process. In this way, the resistance of the element can be calculated, assuming that any parameter (area, yield stress, length, etc.) can acquire variable values.

In 1995, the SBRA team moved to San Jose State University in California, where it carried on its work, receiving support from both the university and the AISC (American Institute of Steel Construction). This lead to the book "Simulation-Based Reliability Assessment" (Marek et al., 1995), introduced to the market in autumn 1995. During the following decade, the SBRA method was rapidly reaching new and wider acceptance, thanks to the cooperation with the Technical University in Ostrava, Czech Republic, and to the international project TeReCo (Teaching Reliability Concept). The work of the international team and of the eager students brought hundreds of publications and examples of the application of the method (http:// www.sbra-anthill.com) (some of them described in detail in section 3).

\section{Representation of Variables and Results SBRA}

At first sight, the formulae used in the SBRA method do not appear to produce any amazing discoveries. They are very simple, mostly containing relationships derived from mechanics and structural analysis, with no complicated semi-empirical coefficients. However one of the crucial advancements facilitating the entire simulation is the way of defining variables.

\subsection{Representing loads}

The Monte Carlo simulation process needs a clearly defined set of variables. Therefore, the loads are determined by their Load Duration Curve, which is a curve that quantifies a specific load in time (during the lifespan of the structure). Such curves are then converted into histograms to increase the speed of the simulation. The following figures show the Load Duration Curves for four types of loads.

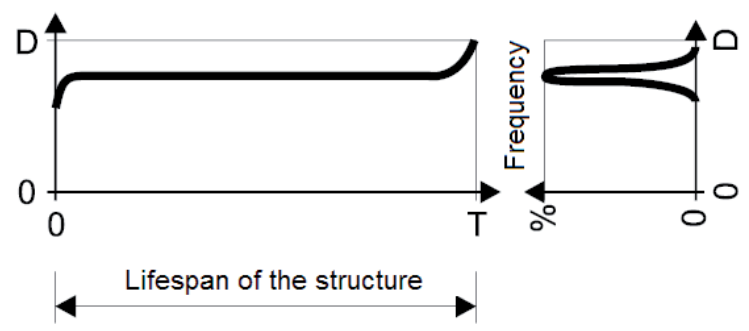

Fig. 1: Load duration curve for Dead Load.

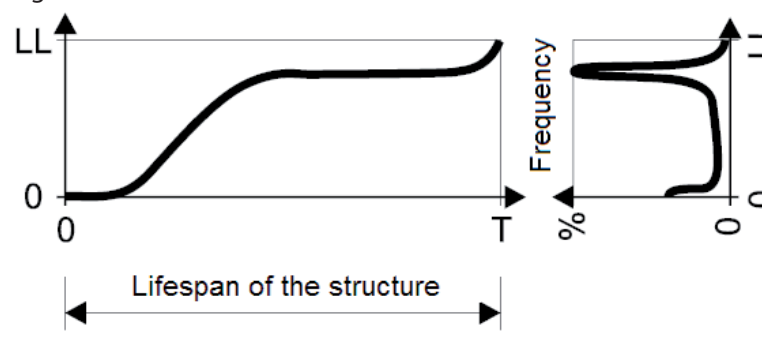

Fig. 2: Load duration curve for Long-lasting Load. 


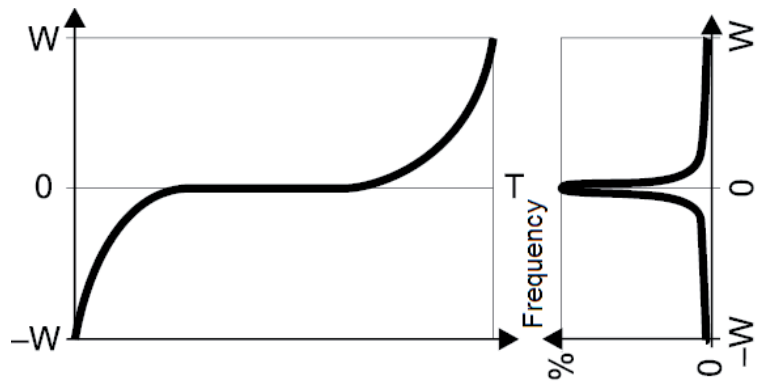

Fig. 3: Load duration curve for Wind Load.

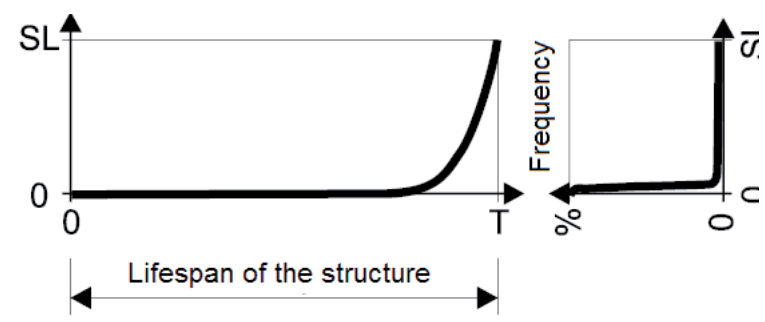

Fig. 4: Load duration curve for Snow Load.

Such histograms (as seen in Figs. 1,2,3,4) can be easily stored in databases, so designer may choose the appropriate histogram for any loading combination. In the Czech Republic, this data has been gathered for almost twenty years. As in the case of wind loads; thanks to the cooperation with Dr. L. Nemec from the Czech Hydrometeorological Institute, very sophisticated diagrams connecting the wind speed and frequency in different directions were obtained see Fig. 5.

At the moment, research is being done with the aim to to enable a similar "map of histograms" for snow load. Therefore, the designer would receive a powerful tool to obtain very precise data for a specific placement of the designed structure.

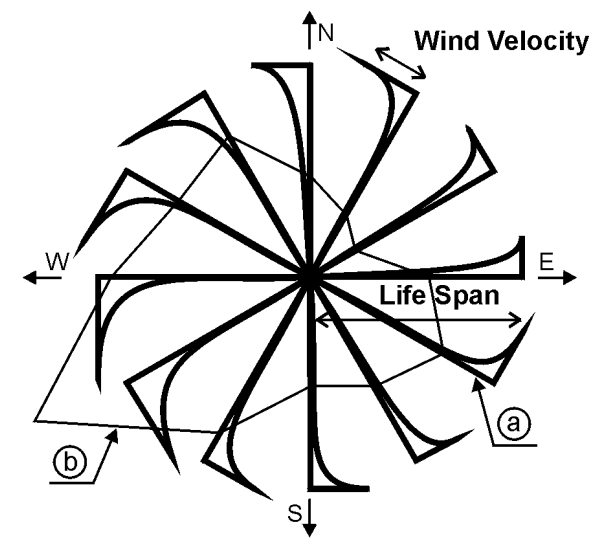

Fig. 5: Wind speed and frequency.

\subsection{Parameters of the materials and elements}

We could easily argue that virtually any parameter of the material or element (area, moment of inertia, yield stress, length, even imperfections) will assume some degree of randomness. The designer's work should be to choose the cases where the random behavior can be neglected and where it could be of great importance for the structure. The main focus should be directed towards the correct representation of yield stress, using histograms provided by the producers. Again, the use of databases is suggested for the future.

\subsection{Representation of results}

The SBRA method strictly adheres to its probabilistic approach. Therefore, any result can be expressed by histograms. This creates a very obvious link to the probability of failure: defining the load effect as $\mathrm{S}$ and the structural resistance as $\mathrm{R}$ gives the safety function:

$S F=R-S$

The probability of failure can then be expressed by a simple ratio between the number of results that do not fulfil the safety function (1) and the total number of results, as shown by the following formula (2) and especially by Fig. 6.

$P F=\frac{N_{\text {fail }}}{N_{\text {tot }}}$

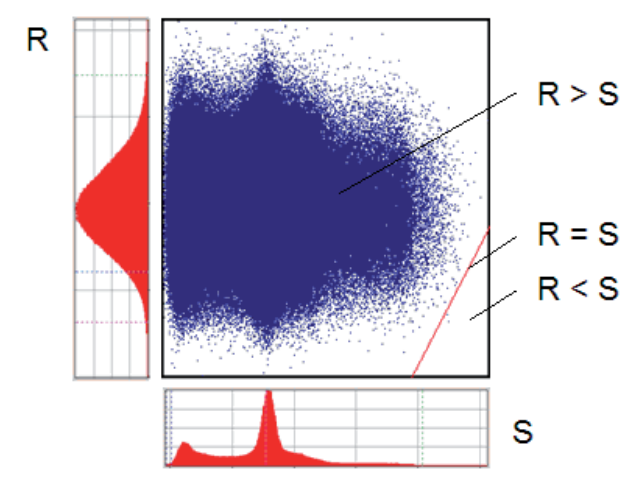

Fig. 6: Graphical representation of the results of the simulation rocess.

\section{Pilot Examples of theApplication of SBRA}

The SBRA method has evolved significantly during the past 20 years. The first applications involved statically determined structures subjected to a combination of loads. These examples point out significant discrepancies among the applied standards (Konečný, 
2001). Today the method can be used to evaluate probabilities of failure along the elements in a statically indeterminate frame (see section 3.1. or (Pustka et al., 2002; Vaclavek et al., 2010)) or the structural durability (see section 3.2. or (Marek et al., 2003)).

\subsection{Calculation of a statistically indeterminate frame}

In this example (Pustka et al., 2002), the probability of failure along the main elements composing a twostorey frame (see Fig. 7) was evaluated. The types of loads are described in Table 1. The evaluated equations provide for a set of values for all the inner forces in the entire structure, as seen in Fig. 8.

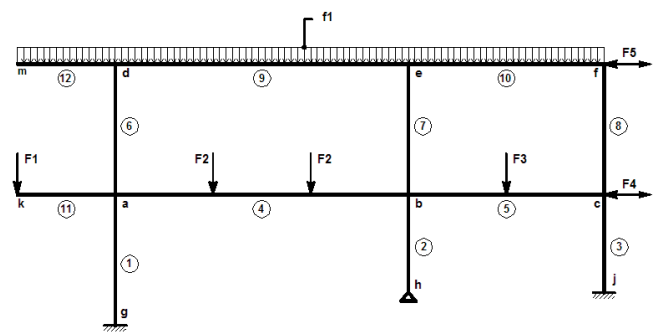

Fig. 7: Statically indeterminate frame.

Table 1: Acting loads

\begin{tabular}{|c|c|}
\hline Load & $\begin{array}{c}\text { Type of Load } \\
\text { F1 }\end{array}$ \\
\hline F2 & Short-lasting load \\
\hline F3 & Long- and short-lasting load \\
\hline F4 & Long- and short-lasting load \\
\hline F5 & Wind load \\
\hline f1 & Wind load \\
\hline
\end{tabular}

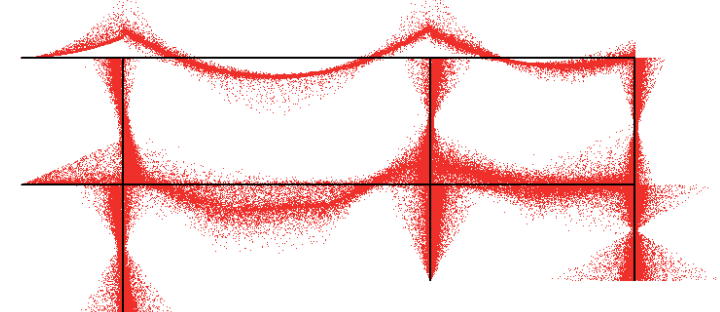

Fig. 8: Bending moment scatter.

The nature of the simulation also offers the possibility of a direct transition towards reliability. Having a clearly defined set of results (i.e. the resistance and the load effect) available for each section makes possible the evaluation of the probability of failure as defined by the equation (2) along the structural components. The final graphical output demonstrating the probability of failure in various points of the frame can be found in Fig. 9.

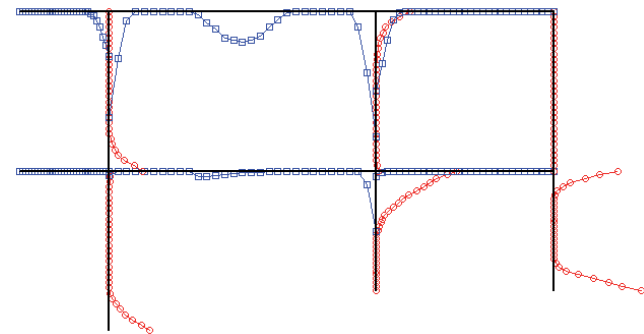

Fig. 9: Probability of failure.

\subsection{Determination of the durability of a structure}

The durability of a steel structure (Marek et al., 2003) can be an important issue in scores of cases, such as, if the structure is damaged (by corrosion, fatigue, etc.) or if decisions about major modifications or even about dismantling must be made. In this case, the SBRA method can simulate the decay of the structural resistance on one side and an eventual change in load conditions on the other side. Therefore, a gradual increase of the probability of failure can be observed as shown in Fig. 10.

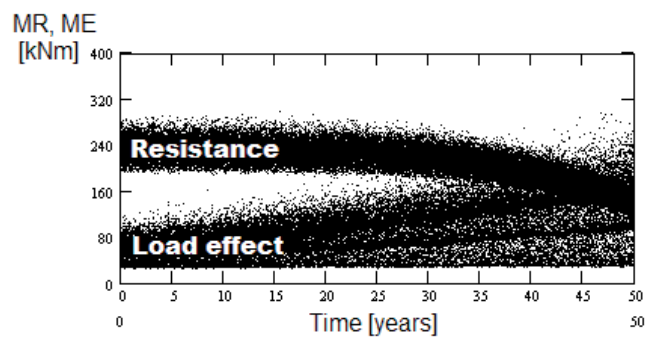

Fig. 10: Durability of a structure in time.

\subsection{Steel beam with overhang - comparing SBRA and the Eurocode}

The way SBRA uses the Monte Carlo simulation allows for several simplifications that are not possible if deterministic methods are used. A simple example of a steel beam with overhang (see Fig. 11, (Marek et al., 2004)), can be used.

Using the Eurocode (Del Corso et al., 2000), the designer should consider 9 different combinations given by the equations 6.10, 6.10a and 6.10b as stated in the Czech National Annex. Therefore, nine different sets of values for inner forces and deformations will be obtained as shown in Fig. 12. 


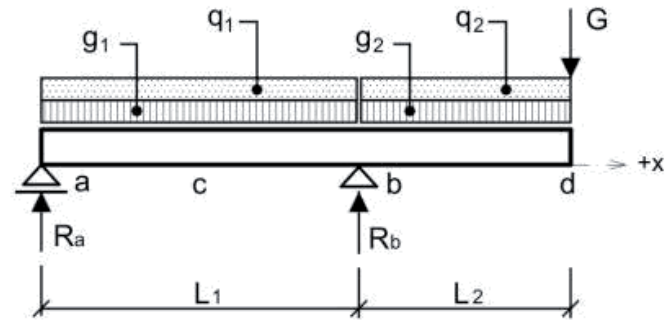

Fig. 11 Steel beam with overhang.
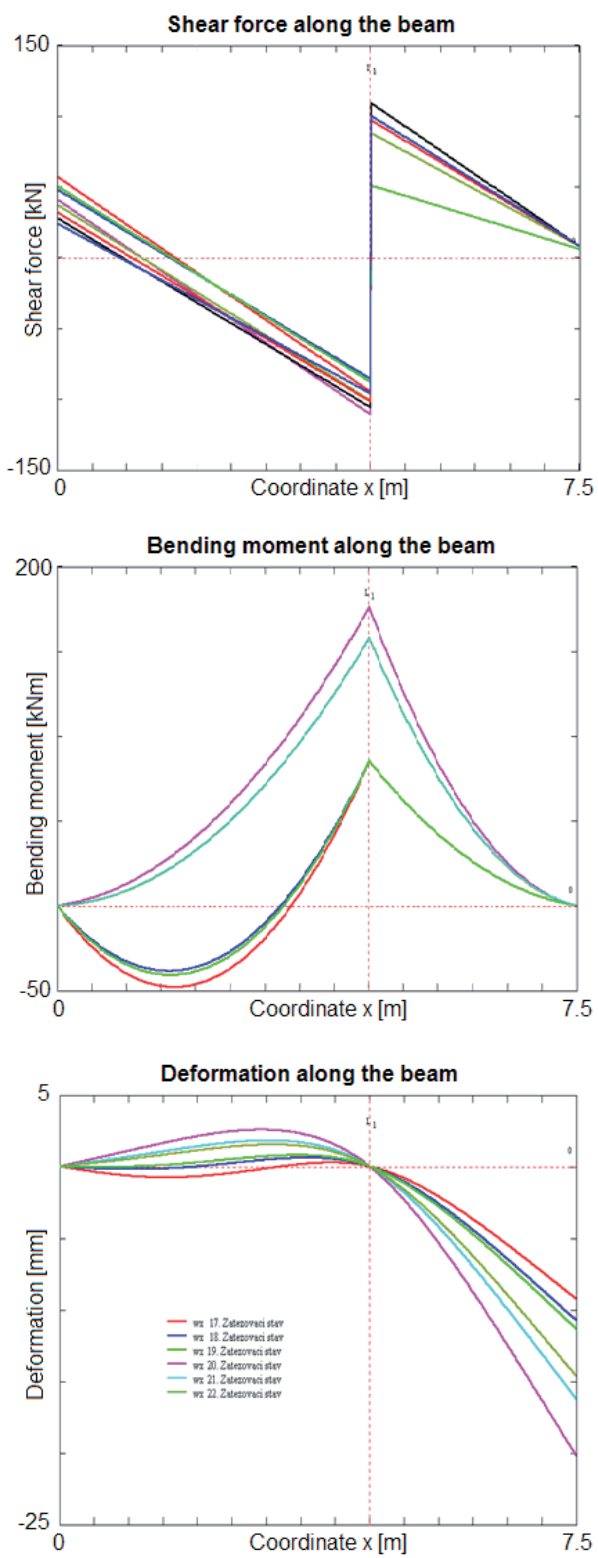

Fig. 12 Shear force, bending moment and deformation along the steel beam.
For the same beam, the Monte Carlo simulation tool used by SBRA enables to calculate millions of values, giving a direct link to the probability of failure as stated in equation (2) - see Fig. 13.
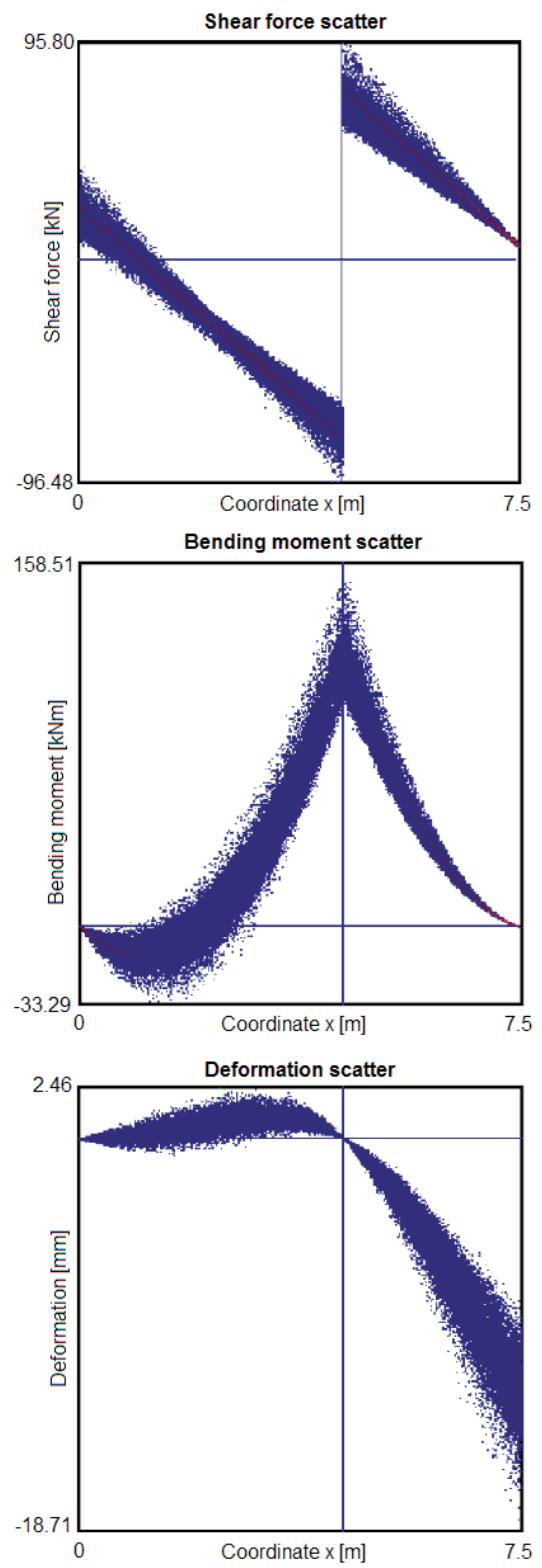

Fig. 11 Steel beam with overhang.

\section{International Cooperation as SBRA Continues to Evolve}

In addition to the project TeReCo mentioned earlier, international cooperation with Professor K. K. Phoon of Singapore began in 2003. Current topics for research 
include studies about the transfer of loads into the subsoil, creating the basis for the use of SBRA in the calculation of foundations.

At the moment (2011) the University of West Bohemia in Pilsen, Czech Republic, is applying for a grant supporting international cooperation together with prof. Achintya Haldar from the Department of Civil Engineering and Engineering Mechanics, University of Arizona, Tucson, AZ.

\section{Conclusion}

In view of the above, it is clear that the potential of the SBRA method increases in sync with the capacity of computer technology. Already today, simpler simulations of millions of steps can be carried out on an average personal computer within minutes, without neglecting such challenging problems as second order theory or residual stress.

During the last years, the complexity of the problems that can be solved with SBRA (Václavek et al., 2010; Marek et al., 2008) has been increasing significantly. In the near future, a transition from the old "prescriptive" structural reliability assessment methods towards qualitatively "higher" methods, such as SBRA, could be considered

\section{References}

Complete list of SBRA publications: http://www.sbra-anthill.com

DEL CORSO, R., GULVANESSIAN, H., HOLICKÝ, M., MARKOVÁ, J., STEENBERGEN, H., VROUWENVELDER, T., Design of structures according to new European codes - Eurocodes, Czech Technical Univ., Prague, Czech Rep., 2000.

KONEČNÝ, P..: Load combinations and assessment of tensioned bar according to EC3 and SBRA; II. ročník celostátní konference: Spolehlivost konstrukcí. Ostrava, Czech Rep., ISBN 80-0201410-3. (Czech), 2001

MAREK P., PUSTKA, D., KONEČNÝ P.: Durability Assessment of Steel Structures using SBRA Method; 8th Int. Conference on Inspection, Appraisal, Repairs and Maintenance of Structures., Singapore, 2003

MAREK, P., PUSTKA, D. (2004): To Probabilistic Reliability Assessment Methods Applicable in Codes. In Metropolitan Habitats and Infrastructure. IABSE Symposium, Shanghai, China, 20.9.2004 24.9.2004. pp. Zürich: ETH Hönggerberg, 2004. ISBN 3-85748-110-2.

MAREK, P., GUSTAR M., ANAGNOS T. - Simulation-Based Reliability Assessment for Structural Engineers. CRC Press, Inc., Boca Raton Florida, 1995.

MAREK, P., KŘIVÝ, V., I-Hong Chen (2008): Safety Assessment of a Steel Frame Using the LRFD and SBRA Methods. In: Pro- ceedings of the 49th AIAA/ASME/ASCE/AHS/ASC Structures, Structural Dynamics, and Materials Conference, Schaumburg, Illinois, USA, 7-10 April 2008. AIAA Meeting Papers On Disc, http//www.aiaa.org/research/DVD

PUSTKA, D., MAREK, P.: Reliability analysis of statically indeterminate steel frame by SBRA method; III. ročník celostátní konference: Spolehlivost konstrukcí. Ostrava,. ISBN 80-0201489-9. (Czech), 2002

VÁCLAVEK, L., I-HONG CHEN, MAREK, P. (2010): Safety Assessment of a Steel Frame Using LRFD and SBRA Methods. Practice Periodical on Structural Design and Construction, Vol. 15, No. 1, February 1, 2010. @ASCE, ISSN 1084-0680

VACLAVEK, L., I-HONG CHEN, MAREK P.: Safety Assessment of a Steel Frame Using LRFD and SBRA Methods; ASCE Practice Periodical on Structural Design and Construction, Feb 2010, Volume 15, Number 1, ISSN 1084-0680. CODEN: PPSCFX. 